\title{
LA RESPONSABILIDAD SOCIAL DEL INFORMADOR EN EL USO DEL LENGUAJE ANTE LA PROLIFERACIÓN DE HECHOS VIOLENTOS EN EL MUNDO DEL DEPORTE
}

\section{SOCIAL RESPONSIBILITY OF THE REPORT ON USE OF LANGUAGE TO THE PROLIFERATION OF VIOLENT ACTS IN THE WORLD OF SPORT}

\begin{abstract}
AUTOR/ES
José Luis Rojas Torrijos: Profesor e investigador de la Facultad de Comunicación. Universidad de Sevilla. Sevilla (España)

jlrojas@us.es
\end{abstract}

\section{RESUMEN}

La comunicación deportiva es un fenómeno singular que se ha desarrollado de forma extraordinaria en los últimos años forjando un lenguaje propio y diferenciado hasta convertirse actualmente en el producto periodístico de mayor éxito. Dada la gran repercusión social de sus informaciones, el periodista deportivo contrae una gran responsabilidad a la hora de emitir una serie de mensajes a partir de unas pautas lingüísticas y éticas que condicionan en gran medida los modelos de expresión y conducta de los ciudadanos, especialmente de los más jóvenes, quienes son los que con más pasión consumen este tipo de información y, por tanto, los más influenciables. Esta responsabilidad social del informador es aún mayor cuando determinados usos lingüísticos y formas visuales de los medios pueden suponer una incitación a que se produzcan comportamientos violentos a raíz de un acontecimiento deportivo.

\section{PALABRAS CLAVE}

Periodismo deportivo - Violencia - Deporte - Comunicación responsable - Uso del lenguaje

\section{ABSTRACT}

Sport communication is a unique phenomenon that has been exceedingly developed for the last years, has created a proper and different language and has turned into the most 
successful journalistic product. Owing to the great social impact of this kind of news, sport journalists contract a high responsibility when they send messages according to some ethical and linguistic guidelines that determine the models of expression and behaviour of citizens to a large extent. This situation is especially significant among the youngsters, because they are the most passionate followers of this sort of information and, consequently, the most easily influenced receivers. This social responsibility is even higher when certain language usage and images shown by mass media may incite people to use violent means because of the result of a sport event.

\section{KEY WORDS}

Sport journalism - Violence - Sport - Responsible communication - Language usage

\section{ÍNDICE}

\section{INTRODUCCIÓN}

2. LA SINGULARIDAD DE LA INFORMACIÓN DEPORTIVA

3. CARACTERÍSTICAS DEL LENGUAJE DEPORTIVO

4. TRATAMIENTO DE LA INFORMACIÓN DEPORTIVA Y CONTENIDOS VIOLENTOS

\subsection{Sensacionalismo}

4.2 Lenguaje vulgar y malsonante

4.3 Lenguaje militar-belicista

4.4 Confusión entre opinión e información

ㄱ 5. GRADO DE RESPONSABILIDAD DEL PERIODISTA DEPORTIVO

2 6. CONCLUSIONES

^ 7. REFERENCIAS BIBLIOGRÁFICAS

\section{INTRODUCCIÓN}

Este artículo responde, en primer lugar, a la necesidad de ahondar en una reflexión académica sobre la comunicación deportiva como proceso único dada su gran capacidad de penetración social, y las peculiaridades del fenómeno periodístico ligado al mundo del deporte. Asimismo, se trata de poner de manifiesto la importancia del lenguaje deportivo, que se ha desarrollado sobremanera en los últimos años a partir de unos códigos y unas pautas que no siempre se corresponden con lo considerado como idiomática y éticamente correcto, pero que condicionan en gran medida los modelos de expresión y conducta de los ciudadanos, especialmente de los más jóvenes, porque estos son los que con más pasión consumen este tipo de información y, por tanto, los más influenciables y vulnerables. 
Igualmente, pretende analizar las estrategias con las que se corresponden los contenidos informativos deportivos y la posible relación causa-efecto entre determinados usos lingüísticos y formas visuales de los medios (sensacionalismo, lenguaje militarbelicista, expresiones malsonantes y vulgares, etc.) y los comportamientos violentos que se producen en los estadios y en las calles a raíz de un acontecimiento deportivo.

Se trata de un problema de candente actualidad que resulta necesario abordar, primero porque ha adquirido una dimensión que va más allá de lo deportivo y amenaza con quebrantar la convivencia en determinadas ciudades1. Segundo, porque se produce en uno de los ámbitos periodísticos menos autorregulados en España e Hispanoamérica, donde solo tres medios de comunicación especializados poseen libro de estilo2 y donde las transmisiones deportivas se desarrollan sin que las principales cadenas de televisión impongan unos mínimos límites éticos que les son exigibles por su condición de servicio público.

\section{LA SINGULARIDAD DE LA INFORMACIÓN DEPORTIVA}

El periodismo deportivo, que se ha desarrollado en los últimos tiempos de una forma extraordinaria por la demanda social que suscita el deporte a todos los niveles, es con diferencia el más consumido y el de mayor alcance social. Según recoge el Estudio General de Medios (EGM), en España, Marca es el diario de pago más leído con 2.805.000 lectores diarios y entre las nueve cabeceras con más difusión, sin contar los gratuitos, hay

\footnotetext{
${ }^{1}$ La proliferación de hechos violentos en el ámbito deportivo ha hecho que los gobiernos promulguen leyes dirigidas a atajar el problema. Este es el caso de España, donde entró en vigor, en julio de 2007, la Ley contra la violencia, el racismo, la xenofobia y la intolerancia en el deporte. Este texto aportó un nuevo enfoque a la normativa existente al ampliar el concepto de violencia en los espectáculos deportivos incorporando los comportamientos racistas, xenófobos o intolerantes, e inició su desarrollo reglamentario con un Real Decreto en 2008 por el que se creó la Comisión Estatal contra la Violencia, el Racismo, la Xenofobia y la Intolerancia en el Deporte, un órgano colegiado presidido por el Ministerio del Interior y el Consejo Superior de Deportes cuya actividad se dirige a prevenir, controlar y sancionar actitudes violentas en acontecimientos deportivos, tanto del ámbito profesional (Ligas de fútbol de Primera y Segunda División, y Liga ACB de baloncesto masculino) como del no profesional. Así, por ejemplo, según recoge la memoria de la temporada 2008/2009 elaborada por la citada comisión, se contabilizaron 35.149 integrantes de grupos de riesgo que se desplazaron a otra ciudad para ver a su equipo; hubo 1.143 propuestas de sanción, la mayoría de las cuales correspondió a promover o participar en altercados e insultar o agredir a policías o vigilantes de seguridad; 518 expulsados y 88 detenidos; y 57 partidos de fútbol declarados de alto riesgo. En lo que respecta al ámbito de deporte aficionado, quedaron registrados incidentes en 264 encuentros, en casi su totalidad de fútbol.

2 El diario barcelonés Mundo Deportivo dispone desde 1995 de un libro de estilo de uso interno, realizado a partir de un estudio del catedrático Josep Maria Casasús. La segunda publicación deportiva española en contar con un manual de estilo específico fue el semanario futbolístico barcelonés Don Balón. La obra vio la luz en el año 2004 y es de circulación y uso interno. En América, el único medio especializado que cuenta con una herramienta de estas características es la revista argentina El Gráfico desde el año 2000.
} 
cuatro de información deportiva3, cuya suma alcanza casi los cinco millones de lectores. Esta tendencia también se reproduce en las ediciones digitales de estos cuatro diarios, que se sitúan entre los trece sitios españoles de Internet más visitados cada mes con 6.716.000 usuarios únicos4.

Asimismo, la radio temática deportiva (Radio Marca) se ha hecho un sitio en el dial (con una media de 527.000 oyentes, es la séptima tras las principales cadenas musicales de FM). En cuanto a los programas de la radio generalista, los dedicados a deporte también copan los primeros puestos. Entre ellos, sobresalen los de la Cadena Ser, como El Larguero con una audiencia media de 1.261 .000 oyentes y Carrusel Deportivo, que alcanza las 1.978.000 personas los sábados y las 2.281.000 los domingos. Por otra parte, los espacios televisivos más vistos de cada mes y cada año son las retransmisiones deportivas 5 .

También en la mayor parte de los países americanos de habla hispana el deporte constituye un producto preferente para una mayoría de los ciudadanos, hasta el punto de que la prensa diaria especializada ha florecido en los últimos años con multitud de cabeceras. Tales son los casos de Olé, primer diario deportivo argentino fundado en el año 1996, o del diario venezolano Líder que salió a la calle en 2004 y que coexiste con el decano de la prensa deportiva diaria en este país, Meridiano, nacido en 1964 y actualmente uno de los periódicos de mayor circulación nacional ${ }^{6}$.

La eclosión de este tipo de periodismo especializado ha sido muy importante también en países como Perú, donde existen cuatro periódicos especializados en deportes (Goles Perú, Todo Sport, Libero y El Bocón) o México, con otros cinco: Esto, La Afición, Récord, Estadio Deportes y Ovaciones. Igualmente, destacan rotativos especializados

\footnotetext{
${ }^{3}$ Estos diarios son Marca, As, Mundo Deportivo y Sport, los dos primeros con sede en Madrid mientras que los otros dos se editan en Barcelona.

4 Según los datos del Estudio General de Medios (EGM) publicado en abril de 2010 por la Asociación para la Investigación de Medios de Comunicación (AIMC), marca.com es el sitio de Internet más visto en España con 3.131 .000 usuarios únicos cada mes. Este estudio está disponible en la dirección http://www.aimc.es

5 Así volvió a quedar demostrado en 2009, un ejercicio en el que, según señala el informe Análisis Televisivo 2009 de Barlovento Comunicación, los quince programas más seguidos por el público fueron partidos de fútbol, tanto de competiciones nacionales como internacionales. Entre ellos, sobresalió la final de la Liga de Campeones que enfrentó al FC Barcelona y Manchester United, que fue seguida por 13,3 millones de telespectadores y logró una cuota de pantalla cercana al $62 \%$. El récord en la televisión española se sitúa también en otro encuentro futbolístico, la final de la Eurocopa de 2008 entre las selecciones de España y Alemania, que alcanzó una media de 14.482 .000 telespectadores y un share (cuota de pantalla) del 80,9\%. Durante este encuentro, el minuto de oro alcanzó los 17.690 .000 telespectadores y una cuota del $88,6 \%$.

6 Según recoge el informe Tendencias 07 de la Fundación Telefónica, el segundo diario con mayor circulación en Venezuela es el deportivo Meridiano, con 144.413 ejemplares diarios, solo superado por Últimas Noticias, con 166.296, y muy por delante de El Nacional, con 88.905, y el Universal, con 82.709 (datos correspondientes a 2005).
} 
como Deportivo en Chile, Diario Deportivo en Colombia, Diez (Honduras) y el estadounidense Deporte Total.

El desarrollo extraordinario de la información deportiva a ambos lados del Atlántico ha propiciado la creación de un lenguaje sectorial, con multitud de términos y expresiones nuevas, que ha evolucionado con personalidad propia en los últimos años hasta convertirse en terreno de avanzadilla de la lengua española. Efectivamente, los medios de comunicación deportivos contribuyen a diario a ensanchar el idioma creando usos lingüísticos, vocablos y acepciones nuevas que años más tarde, tras generalizarse y pasar a formar parte del acervo léxico común, acaban incorporándose al diccionario.

No obstante, también es considerado como una fuente permanente de problemas idiomáticos y se sitúa en el punto de mira habitual de filólogos y expertos en el uso del lenguaje por el abuso que comete de palabras extranjeras, de formas coloquiales -que en algunos casos llegan a ser incluso vulgares-, así como por la pobreza del léxico empleado y la abundancia de errores gramaticales; rasgos que en algunos casos le han llevado a adoptar determinados usos que se apartan demasiado de la norma culta.

Ante esta situación, las principales instituciones lingüísticas del mundo hispánico como la Asociación de Academias de la Lengua Española, el Instituto Cervantes, la Fundación del Español Urgente (Fundéu) o la Fundación San Milán de la Cogolla, y algunos medios de comunicación, en especial la agencia Efe, presentan el lenguaje deportivo como un ámbito de urgente intervención y vigilancia para procurar un uso correcto del idioma.

De esta forma, han organizado desde principios de los años noventa congresos generales (como los Congresos Internacionales de la Lengua celebrados en Zacatecas (México) en 1997 y en Valladolid (España) en 2001, que se centraron en el español utilizado en los distintos tipos de medios de comunicación) y específicos sobre el idioma en los medios deportivos y han publicado obras que recogen la terminología más utilizada en las principales disciplinas.

Tal como señala Pedro Paniagua (2003, p.9), la información deportiva constituye actualmente una de las especializaciones periodísticas con un mayor número de adeptos e incondicionales y su éxito reside sobre todo en que ha sabido aunar de forma natural información y espectáculo en sus contenidos.

En este sentido, Antonio Alcoba (2005, p.10) indica que ninguna otra actividad genera un mayor volumen informativo que el deporte y que el auge de este tipo de periodismo se debe a que informa sobre "un género específico comprensible a todas las mentalidades a través de un lenguaje universal que todos entienden, producto del espíritu y la filosofía del deporte, como fenómeno cultural más seguido y practicado desde comienzos del siglo pasado y que va en aumento en el siglo que hemos iniciado". 
Néstor Hernández, por su parte, también recalca la trascendencia social de este tipo de periodismo merced, sobre todo, al tipo de lenguaje que utiliza:

"El periodista deportivo contribuye a formar una lengua estándar, apropiada para las clases medias; es el máximo receptor y, a la vez, el máximo innovador; por medio de él muchas construcciones llegan a institucionalizarse, conocida su influencia en el lenguaje hablado. El periodista deportivo ha roto el muro de la incomunicación que otros lenguajes construyeron" (2003, p.16).

\section{CARACTERÍSTICAS DEL LENGUAJE DEPORTIVO}

Con el fin de ser fácilmente entendido por cuantos más mejor mediante el uso de un lenguaje accesible y sencillo, la comunicación deportiva se ha desarrollado en los últimos años de forma vertiginosa marcando tendencias y creando un estilo propio, fundamentado en el ritmo, el color, la originalidad y la espectacularidad de sus propuestas.

Además, con el objetivo de conectar mejor con la audiencia, de captar su atención y fidelizar su consumo, una buena parte del periodismo deportivo en lengua española ha optado decididamente por aproximarse a las formas más coloquiales del idioma y adoptar un estilo de narración que no sólo informe, sino que además sirva de entretenimiento.

A este respecto, el Libro de Estilo de Canal Sur Televisión deja claro cuáles son los parámetros entre los que se ha de mover un periodista deportivo:

"El espectador espera tres cosas de una información deportiva: rememorar lo sucedido, datos novedosos y anécdotas y diversión y distracción, sobre todo si el resultado es favorable. La obligación del periodista es cubrir estas expectativas y mediar entre el público y el deporte sin renunciar al rigor y la seriedad, pero sin olvidar la pasión y la expectación que disciplinas como el fútbol generan" (2004, p.106 y ss.).

\section{TRATAMIENTO DE LA INFORMACIÓN DEPORTIVA Y CONTENIDOS VIOLENTOS}

La información deportiva, además de haber sido considerada en los últimos tiempos como un campo de conflicto lingüístico y uno de los sectores más desprestigiados dentro del periodismo, ha sido responsabilizada de contribuir mediante 
un uso desacertado del lenguaje al progresivo aumento de la violencia dentro y fuera de los terrenos de juego.

Cada vez se pronuncian más voces en este sentido, entre ellas la de Bernardo Nespral, quien esgrime que la reproducción de comportamientos violentos en los espectáculos deportivos no debe limitarse sólo a los jugadores, dirigentes, organizadores y a los aficionados, sino que puede incluir también a los periodistas (1999, p.65).

Por su parte, Jesús Castañón (2000) entiende que "los medios de comunicación son acusados de recurrir a la violencia y los valores heroicos como reclamo para provocar el interés del espectador, además de convertir una simple competición en un espectáculo de pasiones".

Esta amalgama de sensaciones que rodea al mundo del deporte y sus ramificaciones violentas han motivado multitud de reflexiones, muchas de las cuales se centran en el fútbol al tratarse de la disciplina de mayor tirón popular. Entre estos trabajos, destacan los artículos de Manuel Vázquez Montalbán, quien halla en el deporte rey el terreno abonado para el desarrollo de la violencia por diversos motivos:

"El fútbol ha sido el derecho a la épica, ejercido a tontas y a locas por el pueblo. Ha sido, y es, un instrumento de desviación de la agresividad colectiva hacia un cauce no político. Pero también ha servido, juzgado desde otra perspectiva, como válvula de escape de las frustraciones del hombre de la calle y, por lo tanto, ha cumplido un papel higiénico sobre la prenormal conciencia social del país" (2006, p.75).

En esta misma línea de pensamiento, se sitúa el periodista argentino Sergio Levinsky (2002, p.50), quien desglosa las principales críticas que recibe en el mundo entero la prensa deportiva, entre las que señala la utilización del deporte como factor de venta, el sensacionalismo, la promoción de violencia, la escasa formación profesional y la inculcación de exagerados sentimientos nacionalistas y patrioteros.

Efectivamente, la creciente tendencia a convertir la información en puro espectáculo y la contaminación de los géneros periodísticos con fórmulas sensacionalistas han sido señalados en reiteradas ocasiones por las propias asociaciones y colectivos profesionales como algunos de los problemas más preocupantes del periodismo actual (Durán 1996, p.107).

A continuación, enumeraremos las principales características del lenguaje periodístico deportivo y determinados rasgos de su presentación visual ante la audiencia que pueden conducir a la reproducción de conductas violentas en torno a las competiciones. 


\subsection{SENSACIONALISMO}

El sensacionalismo es una característica que especialmente en España suele asociarse a la prensa especializada en deporte ante la inexistencia en este país de cabeceras de información general que, al igual que ocurre en países como Reino Unido, Alemania u Holanda, se rijan en su maqueta y en su estilo por esta técnica para conseguir más audiencia. Los diarios deportivos pasan así a tener la consideración de prensa de marcado carácter popular (Ortiz 2005, p.29).

De esta forma, la prensa deportiva, con el objetivo de entretener tanto o más que informar y de copar cuanto más mercado mejor dada la creciente competencia publicitaria, ha evolucionado adoptando algunos rasgos típicos de la prensa más populista o sensacionalista, a partir de un diseño llamativo que ha ido incorporando color, fotografía y todas las variantes tipográficas posibles.

Esta apuesta formal también repercute en el tratamiento de los contenidos, alterando criterios objetivos de selección y valoración de la información, dentro y fuera del texto; dando cabida y relevancia a aspectos que a simple vista resultarían anecdóticos o secundarios en cualquier otro medio; y descuidando los controles de calidad a la hora de utilizar el lenguaje (Paniagua 2003, p.92).

Sin embargo, para algunos autores, como Álex Grijelmo, el sensacionalismo constituye una técnica más del periodismo, la cual no tiene por qué ser desdeñada siempre:

"No merece el rechazo frontal. Un periódico puede seguir las normas del sensacionalismo $y$, sin embargo, ofrecer informaciones veraces y valiosas. Porque se trata fundamentalmente de una técnica, un estilo, una forma de presentar la realidad y de interpretarla. En España, se suele asimilar sensacionalismo y mentira. Y no ha de ocurrir así necesariamente" (1997, p.531).

En cualquier caso, el sensacionalismo de la prensa deportiva, especialmente la que versa sobre fútbol profesional -que es la materia que ocupa en torno al $80 \%$ de las páginas de los diarios especializados-, no es más que la consecuencia del marco en el que tiende a moverse este tipo de profesional de la comunicación: además de informar, entretener y -teóricamente- formar, debe satisfacer la enorme demanda de noticias de unos aficionados apasionados $\mathrm{y}$, al mismo tiempo, responder a la estrategia comercial de las empresas apelando al consumo de periódicos a través de titulares y portadas espectaculares.

Esta necesidad de llenar amplios espacios informativos es precisamente la razón por la que este tipo de periodismo se nutre de manera recurrente de cruces dialécticos entre protagonistas del deporte (entrenadores, jugadores y directivos), los cuales 
acaparan un espacio preferente y motivan que en días sucesivos la historia se prolongue con nuevas contradeclaraciones impactantes con las que garantizar la venta de un número importante de ejemplares.

De acuerdo con esta estrategia mercantilista de la información, los contenidos de las noticias deportivas suelen incorporar multitud de expresiones y palabras que buscan la exaltación épica de los acontecimientos a través de hipérboles, redundancias o metáforas, pero al mismo tiempo reproducen $-\mathrm{y}$, por tanto, amplifican- la violencia verbal de los protagonistas, lo que puede contribuir peligrosamente a caldear el ambiente previo a la celebración de un partido o torneo importante.

En otras ocasiones, este 'precalentamiento' ambiental se produce a raíz del empleo de términos de carácter peyorativo o con connotaciones violentas. Veamos el ejemplo de la voz 'hooligan', una de las palabras más utilizadas hoy día cada vez que se tratan noticias referidas al fútbol británico. Al contrario de lo que muchas veces dan a entender los medios de comunicación, este vocablo no es sinónimo de 'hincha' sino de 'gamberro', 'ultra' o 'seguidor violento'. Por tanto, no es adecuado generalizar y decir que todos los aficionados de un determinado equipo británico son 'hooligans' sino -puestos a utilizar la palabra inglesa exacta- 'supporters' (Rojas 2007).

\subsection{LENGUAJE VULGAR Y MALSONANTE}

Comentábamos antes la tendencia generalizada del periodismo deportivo de universalizar su lenguaje para hacerlo fácilmente entendible a todos los públicos. No obstante, esta inclinación hacia lo coloquial, más propia del registro hablado que del escrito, también entraña riesgos importantes. El empleo asiduo de expresiones que nacen más desde la inercia y la improvisación que de la reflexión, acomoda al periodista en un estado de laxitud permanente y lo aproxima al error.

Tanto es así que la tendencia hacia lo popular en ocasiones degenera en la utilización de expresiones malsonantes, indecorosas e incluso ofensivas e incitadoras de violencia para el público receptor. Éstas no deberán utilizarse salvo en aquellas contadas ocasiones en que se trate de citas textuales y siempre que procedan por la relevancia de la noticia, es decir, siempre que aporten información. Si no, habrá que aludir a ellas de forma abreviada o eliminarlas (Rojas 2005, p.22).

Sobre esta misma cuestión, Grijelmo señala que el periodista debe mostrar un lenguaje común, en ningún caso vulgar ni pobre, que tienda hacia la precisión y resulte eficaz en la elección de los significados concretos y adecuados:

"Sobre todo en el lenguaje deportivo, los periodistas acuden insistentes a expresiones de la calle que dicen muy poco de su vocabulario 
personal (...) El informador no puede permitir que le contagien las palabras que usan sus amigos o su entorno ("le metía 16 segundos" forma parte de un lenguaje vulgar o de jerga que el redactor no puede asumir)" (1997, p.342).

De esta forma, vemos cómo los equipos 'se ponen las pilas' (trabajan con dedicación), los presidentes tratan de que reine el 'buen rollo' (tranquilidad) y de que no haya 'cabreos' (enfados) en el vestuario, los entrenadores no 'se mojan' (se arriesgan) a la hora de hacer un pronóstico ante rivales 'chungos' (complicados), los futbolistas ya no cuestan millones sino 'kilos' (millones), y los equipos la 'palman' (caen eliminados) y se llevan 'un palo' (una gran decepción) cuando no logran sus objetivos.

Aunque la universalización del mensaje es una máxima en periodismo, el fin no siempre justifica los medios y los niveles léxicos que se alcanzan deben situarse siempre a la altura adecuada. Por eso, la responsabilidad social que contraen los periodistas deportivos, dada la enorme repercusión de sus informaciones, pasa también por no bajar el listón y mantener la riqueza de su discurso. Hay que abogar por un uso disciplinado y equilibrado del lenguaje que salvaguarde la calidad de la información y, con ello, el prestigio y la credibilidad del medio de comunicación ante los ciudadanos.

\subsection{LENGUAJE MILITAR-BELICISTA}

Otro de los rasgos definitorios de la prensa deportiva que también puede constituir una incitación a la violencia, y que se encuentra directamente relacionado con la tendencia al sensacionalismo como técnica informativa en este tipo de periodismo, es el uso generalizado que se hace de un lenguaje más propio del ejército y de la guerra que del denominado 'fair play' y del resto de principios que enarbola el Comité Olímpico Internacional y con los que habitualmente se asocia el mundo del deporte?

Si bien en realidad este uso de términos belicistas se efectúa en clave metafórica con el propósito de exaltar determinados logros y hazañas deportivas, ha originado que muchos autores e instituciones coincidan en prevenir contra los riesgos que conlleva la utilización de estos vocablos y expresiones.

\footnotetext{
7 Según recogen los Principios de la Carta Olímpica, la misión del COI se dirige a promover el olimpismo por todo el mundo. Esta función consiste fundamentalmente en: estimular y apoyar la promoción ética en el deporte y la educación de la juventud a través del deporte, así como dedicar sus esfuerzos y velar para que se imponga el fair play y se excluya la violencia en el deporte; cooperar con las organizaciones públicas y privadas, así como con las autoridades competentes, a través de sus dirigentes, con objeto de poner el deporte al servicio de la humanidad, promoviendo así la paz; oponerse a todo tipo de discriminación que afecte al Movimiento Olímpico; apoyar la promoción de las mujeres en el deporte, a todos los niveles y en todas las estructuras, con objeto de llevar a la práctica el principio de igualdad entre el hombre y la mujer; dirigir la lucha contra el dopaje en el deporte; e incentivar el desarrollo del deporte para todos.
} 
Entre ellos se encuentra el profesor Manuel Ángel Vázquez Medel, quien advierte de los peligros que comporta la primacía actual del espectáculo sobre la información en los contenidos periodísticos deportivos.

"Determinadas prácticas deportivas -especialmente el fútboltransformadas en su proceso mercantil y espectacular desbordan el adecuado equilibro mediático y que amenazan con devorar y parasitar todo tipo de programas radiofónicos y televisivos, en función de aquellos aspectos más destructivos de la práctica deportiva (afirmaciones identitarias de confrontación, rivalidad, voluntad de dominio, excitación irracional del odio,...)" (2008, p.17).

Entretanto, Julián García Candau (1990, p.123) se refiere a "los tres males fundamentales de la información deportiva y que son idénticos a los que afectan a la generalidad de los medios: excesiva tendencia a la opinión, inflación de términos ingleses que deterioran nuestro idioma y proliferación de vocablos propios de la terminología bélica que contribuyen, en un porcentaje no cuantificado, al aumento de la violencia en los estadios".

Por su parte, Jesús Vivas Holgado (1999, pp. 681 y 682) considera que la persistencia de determinados usos del lenguaje del código épico-bélico-militar en el lenguaje deportivo, y en concreto el fútbol, como 'vapulear', 'masacrar', 'acogotar', 'degollar', 'abrumar', 'apabullar', 'arrasar', 'aplastar', 'triturar' o 'pulverizar' "acentúan los rasgos virtuémicos de 'violencia' y 'agresividad' subyacentes en su significación objetiva, de modo que equiparan 'la violencia propia' con la 'destrucción' del equipo rival, como si se tratara de un conflicto bélico cuya connotación arrastra al deporte".

Álex Grijelmo va más allá y señala que la utilización del fútbol y del deporte en general como "sustitutos civilizados de las guerras" y un ámbito hacia el que se han derivado los odios y las simpatías, hace que el periodismo deportivo asuma cada vez más un lenguaje bélico y violento y que con esas palabras se traspasen los sentimientos xenófobos y competitivos de las naciones:

"Hoy en día, las autoridades deportivas y politicas están intentando desterrar la violencia del fútbol. Las agresiones entre hinchas y las muertes colectivas que ya han sufrido varios estadios han movido a la reflexión (...) El poder seductor de estos términos ya ha mostrado su influencia psicológica: los partidos de un Campeonato del Mundo de fútbol se perciben en cada país como una forma de dirimir el honor y la historia nacionales. Una vez que ya se ha logrado desviar hacia el deporte las ansias de guerra de las naciones, hasta relativizarlas, no parece descabellado pensar también en el peligro de que este lenguaje épico y bélico haga que los más desequilibrados de la afición deseen sumarse a una batalla" (2000, pp. 233 y ss.). 


\subsection{CONFUSIÓN ENTRE OPINIÓN E INFORMACIÓN}

Entre los códigos redaccionales que distinguen al periodismo deportivo de otros tipos de periodismo, destaca la permanente mezcla de opinión e información en los textos. La excesiva cercanía y en ocasiones dependencia de las fuentes (jugadores, entrenadores, clubes o representantes) y la supeditación en un alto porcentaje de las noticias al periodismo de agenda (convocatorias, ruedas de prensa, partidos, previas, etc.) ha repercutido en el estilo de contar, que se centra más en comentar que en hacer información.

Esto no sólo confunde y desinforma al público receptor, sino que además origina que el lenguaje resultante tenga una mayor carga emocional y subjetiva $\mathrm{y}$, por consiguiente, parcial, con menos espíritu crítico y casi ningún punto de vista alternativo. La transmisión de una realidad unívoca y la negación de otras (que se asocian a clubes e hinchadas rivales), dirigida a levantar la pasión de la audiencia y de crear un ambiente de lo más favorable al equipo o deportista más cercano o afín, suele realizarse con mensajes directos e impactantes que a veces, por el empleo del imperativo o una adjetivación exhaustiva, adquieren ciertos tintes de agresividad.

A este respecto, resulta bastante ilustrativo lo que indica el Libro de Estilo de El Mundo Deportivo, que se define como modelo de "diario popular-informativo especializado en deportes" y recoge como principios fundamentales la información clara y el lenguaje correcto, la interpretación responsable y basada en los datos, y la separación clara entre información y opinión (1995, pp. 9 y 10).

Esta obra apuesta por "evitar las vacilaciones técnicas en el tratamiento diferenciado que debe aplicarse a los géneros narrativos y a los géneros argumentativos. A lo largo de todas las fases del acto profesional de redacción, el autor debe mantener el propósito de ajustarse a los límites y exigencias de cada modalidad de género. En los textos de información no se deben incluir opiniones personales del periodista, del mismo modo que en los géneros de opinión no pueden predominar los datos o la narración de hechos".

Nos encontramos, por tanto, en un momento de la historia donde el empeoramiento generalizado de las conductas ha reavivado la preocupación por el empleo de un lenguaje no lo suficientemente cuidado en los medios de comunicación que se dedican a informar sobre acontecimientos deportivos. Este tipo de periodismo adquiere un protagonismo especial y una gran responsabilidad porque es el más seguido y, por consiguiente, el que mayor influencia ejerce en los hábitos de conducta y modos de expresión de los ciudadanos, especialmente entre los más jóvenes, que son quienes más tienden a imitar todo lo que sale en los medios. 


\section{GRADO DE RESPONSABILIDAD DEL PERIODISTA DEPORTIVO}

En este sentido, cada vez son más los organismos públicos, como los Consejos Audiovisuales creados en Cataluña, Navarra y Andalucía, y colectivos y foros ciudadanos que en los últimos años han formulado diferentes propuestas para prevenir este tipo de incidentes. Muchas de las pautas y recomendaciones surgidas en estos documentos son de carácter ético y se refieren a la relación que existe entre determinados contenidos que vierten a diario desde los medios informativos y los altercados que se suceden posteriormente dentro y fuera de los estadios ${ }^{8}$.

Entre esas propuestas, destacan las recomendaciones sobre violencia en el deporte elaboradas en 2008 por el Consejo Audiovisual de Andalucía. Este folleto, denominado Violencia en el Deporte y editado en colaboración con la Federación de Periodistas Deportivos de Andalucía y la Confederación Andaluza de Federaciones Deportivas, aspira a convertirse en un breve manual de buenas prácticas entre los profesionales de la información, con el objetivo de fomentar la convivencia y la defensa de los valores tradicionales del deporte también dentro el mundo deportivo, administraciones y comunidad educativa.

En lo que se refiere a los medios de comunicación, esta guía aconseja, por ejemplo, evitar la repetición de imágenes violentas o enfrentamientos ente aficionados o deportistas, para, sin dejar de informar, no caer en el morbo o el sensacionalismo; y la utilización de un lenguaje agresivo o provocador que no apele a bajas pasiones ni entorpezca la convivencia entre aficiones ni altere el orden público.

Asimismo, existen códigos deontológicos, colegios profesionales e instituciones de autorregulación del periodismo que abogan por el imperio de la ética en los medios de comunicación. Los libros de estilo de muchas redacciones recogen normas de ética y deontología, que en algunos casos cuentan con órganos propios que se encargan de su protección y cumplimiento, como son los defensores del lector, el oyente y el telespectador.

Sin embargo, todo este sistema de autorregulación presenta lagunas o incoherencias. Tal como manifiesta el profesor Josep Maria Casasús:

\footnotetext{
8 Según señala Hugo Aznar (Pautas éticas para la comunicación social. Valencia, 2005. Universidad Cardenal HerreraCEU. Págs. 43-59), los primeros documentos que ponen de relieve en España el problema de la influencia de los medios de comunicación en la proliferación de la violencia social fueron los promovidos por la Unesco (Declaración de Granada. "La Educación en medios de comunicación e internet como instrumento para el desarrollo de una cultura de la paz", octubre 2001), el Consejo Audiovisual de Cataluña ("Los valores en los contenidos de los programas dirigidos a la infancia y la juventud". Barcelona: febrero de 2002) y las cadenas de televisión españolas y el Gobierno de la Nación ("Código de autorregulación sobre contenidos televisivos e infancia", firmado en diciembre de 2004). En Andalucía, se constituyó en marzo de 2006 la Comisión contra la Violencia y el Racismo en el Deporte, que entre sus propuestas fundacionales, recoge la formulación de un pacto para la defensa de los valores deportivos y la promoción del lenguaje y el estilo no violento en los medios de comunicación.
} 
"No se interviene en dos modalidades de contenido que transmiten a veces modelos negativos, atávicos, primarios y por tanto torpes de comportamiento: la publicidad, sobre todo de determinadas marcas de automóviles, que contiene imágenes de violencia; y situaciones reales en los espectáculos deportivos, en las que destacan gestos y comportamientos de torpeza: agresiones físicas, actitudes salvajes, gestos insultantes o degradantes" (2006).

En opinión de este autor, el periodismo deportivo, basado en los lenguajes verbal y visual, es hoy uno de los grandes vehículos de la ética entendida como compromiso responsable del individuo con la sociedad.

"El periodismo del siglo XXI no tiene sentido ni razón de ser sin ese compromiso ético que se adquiere con un uso inteligente de las imágenes y de las palabras. Este compromiso ético debe proponerse, como una de sus primeras finalidades, la formación de los niños y los jóvenes en la inteligencia social y en la sabiduría del progreso cívico solidario. La violencia, la insolencia y la grosería son actitudes antiguas, viejas, propias de la anterior generación".

En este mismo sentido, José Barrero (2008, p.37) hace un llamamiento a las obligaciones profesionales y éticas del periodista deportivo para cumplir correctamente con su trabajo y velar por un uso equilibrado y sin excesos del lenguaje que evite crear un ambiente que no favorezca el mantenimiento de la paz y la cordialidad alrededor del mundo del deporte en general, y del fútbol en particular:

"Los periodistas tienen una serie de responsabilidades y obligaciones para cumplir correctamente con su trabajo, primero en la parte profesional y segundo en la parte ética como transmisores de cultura y valores pacíficos. Por sus manos pasa también la buena educación y la transmisión de la cultura de la paz y la concordia, que es todo lo contrario a la cultura de la violencia y el terror".

Tal como afirma Melchor Gutiérrez Sanmartín, la labor del periodista deportivo, dada la trascendencia social de sus noticias y la materia sobre la que informa, es también la de educar y formar en valores:

El papel del periodista deportivo como formador y educador: "El informador deportivo no sólo ha de responder a lo que el público pide, sino que ha de informar al pueblo acerca de valores que están latentes en sus aficiones y que quizá aún no haya descubierto. Hay que darle al pueblo lo que pide, sí, pero después de haber cumplido la obligación de informarle honestamente y educarle" (1995, p.175).

Queda claro, por tanto, que este tipo de periodismo tiene la responsabilidad añadida de ser educador y transmisor de los valores positivos inherentes a la práctica 
deportiva, como el afán de superación, la cultura del esfuerzo, la solidaridad, el compañerismo, la igualdad o el juego limpio; es decir, todos aquellos valores que son pilares básicos de la convivencia y la paz social.

Ante este nuevo panorama de la información deportiva y su creciente influencia social, según los diferentes índices de audiencia, Jesús Castañón (1994) plantea conveniente la creación de un código ético para este tipo de periodismo con vistas a la prevención de problemas relacionados con el dopaje y la violencia social asociada al espectáculo deportivo. "Se trataría de realizar información sobre el espectáculo deportivo, con veracidad y rigor y no de convertir la propia información en un espectáculo".

\section{CONCLUSIONES}

Por todo lo expuesto aquí, es preciso subrayar, en primer lugar, la necesidad de que el periodista deportivo tome conciencia de la enorme responsabilidad social que contrae al emitir una información, interpretación u opinión al ser el espejo de muchos ciudadanos que solo consumen este tipo de contenidos, a partir de los cuales construyen su propia realidad.

En segundo lugar, es necesario que los medios de comunicación deportivos se autorregulen más y que el libro de estilo y los códigos deontológicos sean también una prioridad empresarial, de forma que los periodistas se rijan por unas exigencias profesionales (rigor informativo, competencia en la materia y ánimo de objetividad) y éticas (transmisión de valores pacíficos, uso del lenguaje no violento, no anteposición de intereses personales ni búsqueda de la polémica en la información), que queden más y mejor definidas.

Así, velarán por un uso más responsable de sus contenidos, más alejados del sensacionalismo, del lenguaje vulgar, la jerga militar-belicista y de la confusión entre hechos noticiosos y juicios de valor; todo ello con el fin de fomentar valores como el juego limpio, la tolerancia, la igualdad y la solidaridad y de respetar principios tan básicos y constitucionales como la protección de la infancia y de la juventud.

Esta es la mejor manera de que el periodismo deportivo gane en rigor, calidad y, por tanto, credibilidad entre sus receptores habituales y otros potenciales, y se convierta en un actor social que forme culturalmente y marque tendencias positivas en el decir y hacer de los ciudadanos.

Si el periodismo deportivo, con toda su grandeza y poder de persuasión, apuesta decididamente por la buena conducta y por un uso más inteligente del idioma, contribuirá a que se eviten más incidentes violentos dentro y fuera de los recintos. 


\section{REFERENCIAS BIBLIOGRÁFICAS}

- AlCOBA, Antonio. Periodismo deportivo. Madrid, 2005. Editorial Síntesis. - La prensa deportiva. Tratamiento inédito sobre el género específico del deporte y cómo hacer una publicación deportiva ideal. Madrid, 1999. Instituto Universitario Olímpico de Ciencias del Deporte.

- AZNAR, Hugo. Pautas éticas para la comunicación social. Valencia, 2005. Universidad Cardenal Herrera-CEU.

- BARRERO MUÑOZ, José. Periodistas deportivos contra al violencia en el fútbol, al pie de la letra. Madrid, 2008. Editorial Fragua

- CANAl SUR TELEVISIÓN. Libro de Estilo de Canal Sur Televisión y Canal 2 Andalucía. Sevilla, 2004. RTVA.

- CASASÚS, Josep Maria. La ética en el lenguaje deportivo verbal y visual en el Encuentro El idioma español en el periodismo deportivo. Sevilla, 2006. Universidad Internacional Menéndez Pelayo.

- CASTAÑÓN, Jesús. Nuevos retos del periodismo deportivo. Valladolid, 1994. Edición del autor. Disponible en Internet en la dirección: http://www.idiomaydeporte.com/libro4.htm - "El juego de la violencia verbal en el fútbol". En: el I Congreso Nacional de Peñas de Fútbol. Oviedo, 2000.

- CONSEJO AUDIOVISUAL DE ANDALUCÍA. Violencia en el deporte. Sevilla, 2008.

- DURÁN GONZÁLEZ, José. El vandalismo en el fútbol. Madrid, 1996. Gymnos.

- EL MUNDO DEPORTIVO. Libro de Estilo. Barcelona, 1995. El Mundo Deportivo.

- GARCÍA CANDAU, Julián. El lenguaje en la información deportiva. En: AA VV. El idioma español en las agencias de prensa. Madrid, 1990. Fundación Germán Sánchez Ruipérez.

- GRIJELMO, Álex. La seducción de las palabras. Madrid, 2000. Editorial Taurus - El estilo del periodista. Madrid, 1997. Editorial Taurus.

- HERNÁNDEZ ALONSO, Néstor. El lenguaje de las crónicas deportivas. Madrid, 2003. Editorial Cátedra.

- LEVINSKY, Sergio. El deporte de informar. Buenos Aires, 2002. Editorial Paidós. 
- MARÍN MONTÍN, Joaquín (coord.). Imagen, comunicación y deporte. Una aproximación teórica. Madrid, 2008. Visión Libros.

- NESPRAL, Bernardo. Derecho de la Información. Periodismo, deberes y responsabilidades. Buenos Aires, 1999. Editorial BdeF.

- ORTIZ, Sonia. Premsa esportiva: informació o espectacle? (Prensa deportiva: ¿información o espectáculo?). En: Capçalera. Revista del Col.legi de Periodistes de Catalunya, $\mathrm{n}^{\circ}$ 128. Barcelona. 2005. Págs. 28-35.

- PANIAGUA SANTAMARÍA, Pedro. Información deportiva. Especialización, géneros y entorno digital. Madrid, 2003. Editorial Fragua

- ROJAS TORRIJOS, José Luis. La información y el deporte. Libro de estilo para la prensa deportiva andaluza. Sevilla, 2005. Aconcagua Libros -"Palabras de fuego". Málaga, 4 de abril de 2007. Basketconfidencial.com

- VÁZQUez MEDEL, Manuel Ángel. el Consejo Audiovisual de Andalucía y el deporte. En: MARÍN MONTÍN, Joaquín (coord.). Imagen, comunicación y deporte. Una aproximación teórica. Madrid, 2008. Visión Libros. Págs. 13-21

- VÁZQUeZ MONTALBÁN, Manuel. Fútbol, una religión en busca de un dios. Barcelona, 2006. De Bolsillo.

- VIVAS HOLGADO, Jesús. El fútbol: léxico, deporte y periodismo. Cáceres, 1999. Universidad de Extremadura. 